\title{
Identifying The Factors Affecting The Performance Of Construction Projects In Wolaita Zone-Ethiopia
}

\author{
Ashenafi Reta ${ }^{1}$ Ashebir Alyew ${ }^{2}$ \\ ${ }^{1}$ Assistant professor, Civil Engineering Department, Wolaita Sodo Univeristy, Ethiopia \\ Email id: hiashe@gmail.com \\ ${ }^{2}$ Assistant professor, Civil Engineering Department, Wolaita Sodo Univeristy, Ethiopia \\ Email id: ashebiralyew@gmail.com
}

\begin{abstract}
Performance indicators of construction project are used to measure overall performance in construction projects. These indicators can then be used for benchmarking purposes, and will be a key element of any organization's move towards attaining quality practice in order to overcome performance problem.The results of a questionnaire survey done to determine factors affecting the performance of construction projects in Ethiopia's Wolaita zone are presented in this paper. Personnel from consultants, owners, and contractors involved in construction projects were among the survey's respondents. The outcome of the study outlines Availability of personnel with high experience and qualification, Availability of resources as planned through project duration, Average delay because of closures and materials shortage, Conformance to specification and Leadership skills for project manager as the top ranked key factors that affect performance of construction project.
\end{abstract}

Key words: Construction project, Performance, Factors

\section{INTRODUCTION}

Construction is one of the most important industries, accounting for around $10 \%$ of the gross domestic product in developed countries ( Navon Ronie, 2005). Because it involves a large number of parties such as consultants, clients, contractors, stockholders, stakeholders, and regulators, the construction industry is complex. Using national economies has an impact on the construction industry's performance ( Navon Ronie, 2005). Time, cost, quality, client satisfaction, productivity, and safety are all elements that influence performance. Construction industry in Ethiopia suffers from many problems and complex issues in overall performance such as bad overall performance because of delay due to (closures, change of drawings and amendment of the design.), poor relations and coordination; poor administration and leadership; inadequate infrastructure, inappropriate participants; absence of motivation, control, monitor or decision making systems;political problems; economic conditions and cultural issues.

In Ethiopia there are many construction projects fail in performance. In addition, overall performance measurement systems are now not tremendous or efficient to overcome this problem. Construction projects overall performance problem appears in many components in Ethiopia. There are many constructed projects fail inprice performance, in time performance and others fail in different performance indicators. There are many projects which completed with poor performance due to the fact of many evidential motives such as:amendment of the design and drawing,nonavailability of materials, barriers via client road closure, additional works, waiting the decision, handing over, amendments in Bill of Quantity, delay of receiving drawings andvariation order.

In this study, factors that affect the routine of construction project in Ethiopia will be identified. Performance indicators are used to measure overall performance in construction projects. These indicators can then be used for benchmarking purposes, and will be a key element of any organization's move towards attaining quality practice in order to overcome performance problem. However, this study targets at perceive the elements and attributes affecting the performance of building projects in wolaita area and to gain major criteria and indicators to measure performance. 


\section{OBJECTIVE}

The objective of this study is to identify the factors affecting the performance of construction projects in wolaita zone.

\section{LITERATURE REVIEW}

Key performance indicators include factors such as time, cost, quality, client satisfaction; client changes, business performance and safety in order to enable measurement of project and organizational performance throughout the construction industry. This information can then be used for benchmarking purposes, and will be a key component of any organization move towards achieving best practice (Department of the Environment, Transport and the Regions (DETR), KPI Report for the Minister for Construction by the KPI Working Group, January 2000). (Lehtonen Tutu Wegelius, 2001)Stated that performance measurement is a current issue in academia, as well as in business community. (Samson M \& Lema NM, 2002)Stated thatKey performance indicators are very important in order to deliver value to stakeholders. So, companies must be sure they have right processes and capabilities in place. The key performance indicator also allow to trace which processes and capabilities must be competitively and distinctive, and which merely need to be improved or maintained. In order to describe the key performance indicators throughout the lifetime of a project, five key stages have been identified as commit to invest, commit to construct, available for use, end of defect liability period, end of life time of project (Department of the Environment, Transport and the Regions (DETR), KPI Report for the Minister for Construction by the KPI Working Group, January 2000)

Performance indicators and its measurement had been studied for several years. (Karim K \& Marosszeky M, 1999)Defined performance measurement as an operational management accounting including financial and nonfinancial performance indicators. (Karim K \& Marosszeky M, 1999)Stated that performance measurement is a process of re-thinking and re-evaluation of business processes to achieve significant performance improvements of projects. (Reichelt Kimberly \& Lyneis James, 1999)Defined performance measurement as a model which treat project as the complex dynamic system. The key performance indicators are identified by (Department of the Environment, Transport and the Regions (DETR), KPI Report for the Minister for Construction by the KPI Working Group, January 2000) as an applicable indication of project and/or company levels. In some cases the company indicator is the average value of that company `s project indicators. (Thomas Ng S \& Li Wentao, 2006) Defined performance measurement as monitoring and controlling of projects according to regular basis. (Ugwu O.O. \& Haupt T.C, 2007) Classified the key performance indicators as site-specific and project-specific. (Lehtonen Tutu Wegelius, 2001) Stated that performance measurement is a basis for progressive improvement and monitoring of company productivity. (Kuprenas John A, 2003) Stated that project performance measurement means an improvement of cost, schedule, and quality for design and construction stages ( Navon Ronie, 2005)defined performance measurement as a comparison between the desired and the actual performances. (Chan Daniel w. m. \& Kumaraswamy Mohan M, 2002) Remarked that project performance measurement include time, budget, safety, quality and overall client satisfaction.

According to previous studies, concepts and definitions, it can be stated that the overall performance dimension is a method consist of factors as Key Performance Indicators such as time, cost, quality, customer satisfaction; productivity and security in order to enable measurement of current organizational challenge performance and to acquire large overall performance enhancements of future projects. The failure of any construction project is in the main related to the troubles and failure in performance. Moreover, there are many motives and elements which attribute to such problem.

(Kim Du Y, Han Seung H, kim Hyoungkwan, \& Park He, 2008) Stated that international construction projects performance is affected by more Complex and dynamic factors than domestic projects; frequently being exposed 
toserious external uncertainties such as political, economic, social, and cultural risks, as well as internal risks from within the project. ( Navon Ronie, 2005)Remarked that traditional project performance control is usually generic (e.g., cost control techniques). It relies on manual data collection, which means that it is done at low frequency (normally once a month) and quite some time after the controlled event occurred (i.e., not in real-time). Moreover, manual data collection normally gives low- quality data. (Okuwoga Adeyinka A., 1998) Identified that the performance problem is related to poor budgetary and time control.

Broadly speaking Success of construction projects relies upon on success of performance. (Cheung Sai On, Suen Henry C.H. , \& Cheung Kevin K., 2004) Identified project performance categories such as people, cost, time, quality, safety and health, environment, client satisfaction, and communication. (Chan Daniel w. m. \& Kumaraswamy Mohan M, 2002) Stated that construction time is increasingly important because it often serves as a crucial benchmarking for assessing the performance of a project and the efficiency of the project organization. (Thomas Ng S \& Li Wentao, 2006) Identified the main performance criteria of construction projects as financial stability, progress of work, standard of quality, health and safety, resources, relationship with clients, relationship with consultants, management capabilities, claim and contractual disputes, relationship with subcontractors, reputation and amount of subcontracting.

(Jouini Sihem Ben Mahmoud, Midler Christophe, \& Ga, 2004) Stated that managing speed in engineering, procurement and construction projects is a key factor in the competition between innovative firms. (Chan Daniel w. m. \& Kumaraswamy Mohan M, 2002) Stated that a number of unexpected problems and changes from original design arise during the construction phase, leading to problems in cost and time performance. (Love Peter E. D., Tse Raymond Y. C. , \& Edwards Da, 2005) Examined project time-cost performance relationships by using project scope factors for 161 construction projects that were completed in various Australian States. It is noticed that gross floor area and the number of floors in a building are key determinants of time performance in projects. Furthermore, the results indicate that cost is a poor predictor of time performance.In general we can summarize the factors affecting the performance of construction project as pinpoint by different scholars. These includes time, cost, productivity, quality, safety and health, client satisfaction, Environment and people.

\section{METHODOLOGY}

A wide range of employees participating in construction projects in the Wolaita zone were targeted in order to determine the factors affecting construction operations. Project managers, consultants, contractors, client representatives, and construction managers were chosen at random. Previous exploratory research conducted in construction projects in different area of the world were used to create a questionnaire. It was organized using a priority scale ( $1=$ extremely low, $2=$ low, $3=$ medium, $4=$ high, and $5=$ =xtremely high). The survey was sent to both public and private organizations, including building owners, consulting firms, and contractors working on construction projects. A random sample of clients, consultants, and contractors received the questionnaire. The following is a description of the sample chosen for each of the three groups:

$>$ Clients include the project's government agency, private organizations, and individual owners,

$>$ Consultants working on building projects and

$>$ Contractors involved in the project.

Respondents were from government and commercial bodies that fund construction projects, as well as the contracting and consulting firms that support them.

\section{DATA ANALYZE}

Similar research used the Relative Important Index (RII) approach to determine the relative importance of various parameters. Based on replies from consultants, owners, and contractors, this method was used to determine the relative importance of identifying factors affecting the performance of construction project in wolaita zone-Ethiopia. 
$\mathrm{RII}=\left(\frac{\sum(W)}{A * N}\right)$

where: $\mathrm{W}=$ the weight given to each factor by the respondents

$\mathrm{A}=$ extremely high $=5$

$\mathrm{N}=$ the total number of respondents.

The RII is used to rank the groups of questionnaire by calculating the average of relative importance index of all factors in the group.

\section{RESULTS AND ANALYSIS}

Table 1. Factors affecting performance of construction with their RII and Rank at Wolaita zone

\begin{tabular}{|l|l|l|l|l|l|l|}
\hline Factors & \multicolumn{2}{l}{ Consultant } & \multicolumn{2}{l|}{ Owner } & \multicolumn{2}{l|}{ lontractor } \\
\cline { 2 - 7 } & RII & Rank & RII & Rank & RII & Rank \\
\hline $\begin{array}{l}\text { Availability of personnel with high experience and } \\
\text { qualification }\end{array}$ & 0.83 & 2 & 0.81 & 3 & 0.48 & 13 \\
\hline $\begin{array}{l}\text { Availability of resources as planned through project } \\
\text { duration }\end{array}$ & 0.81 & 3 & 0.76 & 5 & 0.5 & 11 \\
\hline $\begin{array}{l}\text { Average delay because of closures and materials } \\
\text { shortage }\end{array}$ & 0.85 & 1 & 0.83 & 2 & 0.89 & 3 \\
\hline Average delay in payment from owner to contractor & 0.64 & 11 & 0.65 & 8 & 0.85 & 4 \\
\hline Cash flow of project & 0.8 & 4 & 0.71 & 7 & 0.84 & 5 \\
\hline Climate condition in the & 0.51 & 14 & 0.49 & 14 & 0.47 & 14 \\
\hline Conformance to specification & 0.78 & 5 & 0.87 & 1 & 0.53 & 10 \\
\hline Cost control system & 0.68 & 8 & 0.74 & 6 & 0.68 & 9 \\
\hline Escalation of material prices & 0.77 & 7 & 0.79 & 4 & 0.91 & 2 \\
\hline $\begin{array}{l}\text { Information coordination between owner and project } \\
\text { parties }\end{array}$ & 0.67 & 9 & 0.59 & 11 & 0.72 & 7 \\
\hline Leadership skills for project manager & 0.78 & 5 & 0.63 & 10 & 0.94 & 1 \\
\hline Participation of managerial levels with decision & 0.61 & 12 & 0.53 & 12 & 0.73 & 6 \\
\hline Quality of equipment and raw materials & 0.65 & 10 & 0.64 & 9 & 0.7 & 8 \\
\hline Sequencing of work according to schedule & 0.52 & 13 & 0.5 & 13 & 0.49 & 12 \\
\hline
\end{tabular}

From the above table the top three factors affecting performance of construction project for the three stakeholders (consultant, owner and contractor) is selected and summarized in the figure below separately labeled as consultant's view, owner`s view and contractors view. 


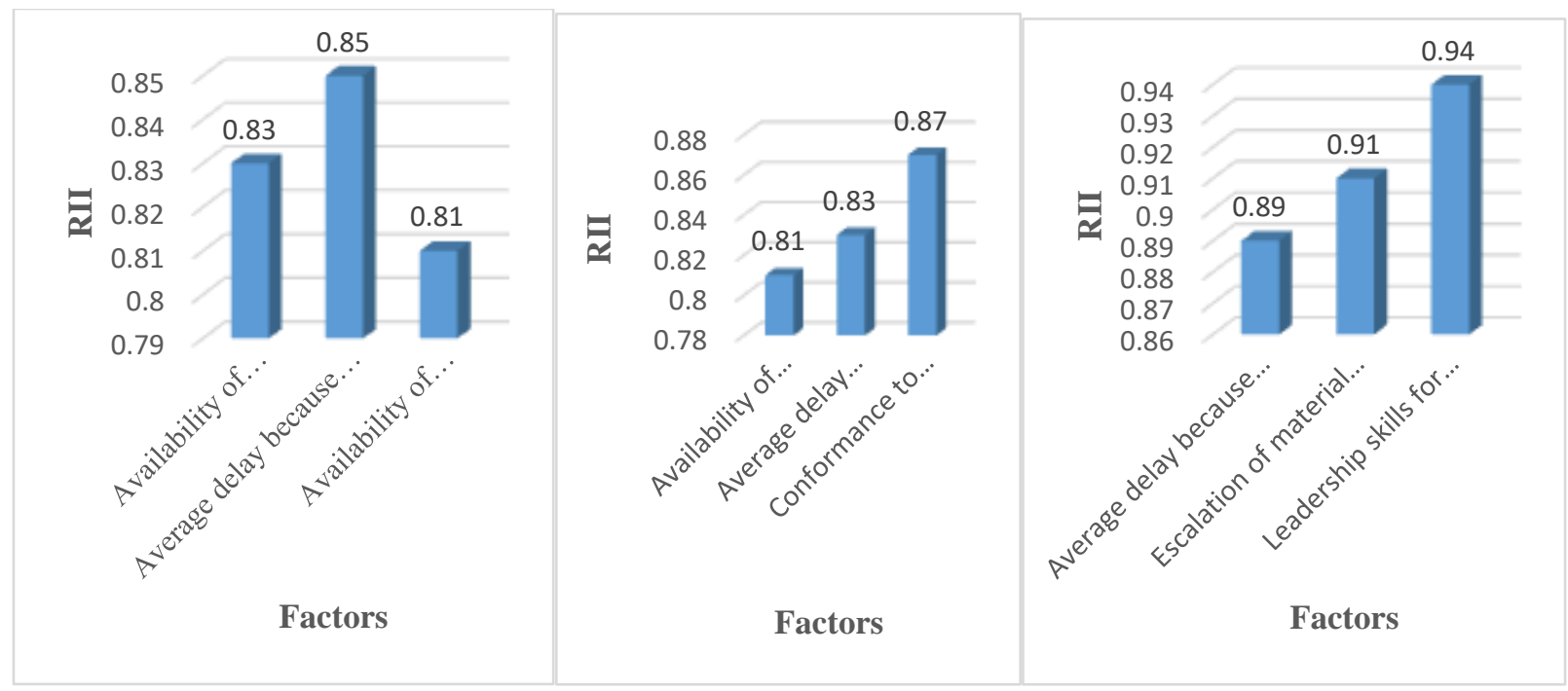

Fig.1 Consultant`s View Fig.2 Owner`s View Fig.3 Contractor`s View

As we can observe from the above table and figures from consultant's point of view Average delay because of closures and materials shortage with $\mathrm{RII}=0.85$ ranked as the first factor affecting performance of construction project. This is due to different complex social and economic problems. In 2021 many buildings in this study area stopped and others indicate poor time performance due to closures and materials shortage.Availability of personnel with high experience and qualification with $\mathrm{RII}=0.83$ and Availability of resources as planned through project duration with $\mathrm{RII}=0.81$ takes the second and third factors. Here the presence of qualified and experienced staffs affects the routine of buildingproject in the positive way i.e. it results in delivering better quality, economical, safe and absence or minimization of project delay. When we come to availability of resource, the presence of resource at the right time and at the right place results in saving time (absence of delay) and becoming Economical.

When we come to owner`s point of view, Conformance to specification with RII $=0.87$ ranked as the first factor affecting performance of construction project. This is because every client whether it is public or private look for executing project according to specification. Whereas Average delay because of closures and materials shortage with RII $=0.83$ takes the second place (This is due to different complex social and economic problems.) and Availability of personnel with high experience and qualification with RII=0.81ranked as thethird factor (Here the presence of qualified and experienced staffs affects the performance of construction project in the positive way i.e. it results in delivering better quality, economical, safe and absence or minimization of project delay).Again according to contractor`s point of view, Leadership skills for project manager with RII $=0.94$ ranked as the first factor affecting performance of construction project. The presence of good leadership skill enables planning, organizing, leading and controlling of of project performance at its best.

Escalation of material prices with RII $=0.91$ takes the second place as factor affecting performance of construction project. This affects the cost performance of a project. In 2021 there are many projects that encountered poor cost performance due to escalation of material that lasts more than a year in this study area. Average delay because of closures and materials shortage with $\mathrm{RII}=0.89$ categorized in the third place as elements that affect routine of building project. 


\section{CONCLUSION.}

The outcomes from literature review and this study are close to each other in pinpointing key indicators affecting construction performance. According to respondents' point of view, Availability of personnel with high experience and qualification, Availability of resources as planned through project duration, Average delay because of closures and materials shortage, Conformance to specification and Leadership skills for project manager are the top ranked indicators that affect performance of construction project in this study area and emphasis should be given to them.

\section{Reference:}

[1] Navon Ronie. (2005). Automated project performance control of construction projects. Automation in Construction, 14, 467-476.

[2] Chan Daniel w. m. , \& Kumaraswamy Mohan M. (2002). Compressing construction duration lessons learned from Hong Kong building projects. International Journal of Project Management , 20, 23-35.

[3] Cheung Sai On, Suen Henry C.H. , \& Cheung Kevin K. (2004). PPMS: a based construction Project Performance Monitoring System. Automation in construction , 13, 361-376.

[4] ( January 2000). Department of the Environment, Transport and the Regions (DETR), KPI Report for the Minister for Construction by the KPI Working Group.

[5] Jouini Sihem Ben Mahmoud, Midler Christophe , \& Ga. (2004). Time-to-market vs. time-to-delivery; managing speed in engineering, Procurement and construction project. International Journal of Project Management , 22, 359-367.

[6] Karim K, \& Marosszeky M. (1999). Process monitoring for process re- engineering using key performance indicators,. International conference on construction process reengineering, CPR 9. Sedney UNSW

.[7] Kim Du Y, Han Seung H, kim Hyoungkwan , \& Park He. (2008). Structuring the prediction model of project performance for international construction projects:A comparative analysis, Expert Systems with Applications. 